Note

\title{
Characterization of an Isolated Bacterium, Providencia sp., Capable of Attaching onto Metal Surfaces
}

\author{
SHOHREH MASHAYEKHAN, TADASHI NORIOKA, MOTOMU NISHIOKA, \\ AND MASAHITO TAYA* \\ Division of Chemical Engineering, Graduate School of Engineering Science, Osaka University, \\ Toyonaka, Osaka 560-8531, Japan
}

Received 7 February 2004/Accepted 10 June 2004

\begin{abstract}
Among microorganisms isolated from different origins, strain WW2 (a wastewater habitant) was selected as a bacterium showing high cell density on metal surfaces $\left(1 \times 10^{8}\right.$ and $1.5 \times$ $10^{8} \mathrm{cells} / \mathrm{cm}^{2}$ on stainless steel and copper, respectively, after two weeks of culture). From the physiological tests and homology analysis based on 16S rDNA, this strain was classified into the Enterobacteriaceae family and identified as a facultative anaerobe, Providencia sp. The attachment of WW2 cells to stainless steel surface was maximized when the growth medium was supplemented with $15 \mathrm{~g} / \mathrm{dm}^{3} \mathrm{NaCl}$. From scanning electron microscopy and energydispersive X-ray spectroscopy observations of the copper wire immersed in WW2 culture without shaking, it was found that the wire surface was covered with black colored deposits mainly composed of copper and sulfur, the latter element possibly originating from the sulfide produced by WW2 cells under local oxygen-limited conditions.
\end{abstract}

Key words : Biofilm-forming bacterium/Metal surface attachment/Providencia sp./Sulfide production.

Some bacterial cells are known to collect on the surfaces of solid materials and proliferate in a form of biofilm, by means of multifactorial events consisting of the adhesion and colonial development of cells as well as the formation of extracellular polymeric substances (EPS). In recent studies it has been stated that the biofilm formation relates closely to a regulatory system, called quorum sensing, in which cell density is monitored through signalizing elements and then modulated gene expression (Kjelleberg and Molin, 2002). This regulatory system can extend our knowledge concerning cellular communications in bacterial consortia.

As for the impact of biofilm, it can cause many kinds of problems related to industry and the environment. Microbially influenced corrosion (MIC) is one such biofilm-mediated problem (Angel, 1999; Dexter, 1993; Ford et al., 1990; Tanji et al., 1999). Since con-

*Corresponding author. Tel: +81-6-6850-6251, Fax : + 81-6-6850-6254 ventional methods of killing bacteria such as using antibiotics are often ineffective against bacteria in a biofilm, a novel strategy based on a better understanding of the properties of biofilm-forming bacteria is needed for protecting materials from MIC.

In the present research, microbial deposits accumulated on solid material surfaces in different environments were collected as sources of bacterial cells capable of attaching onto metal surfaces. A bacterial strain showing relatively high cell density on a stainless steel surface was screened and characterized in terms of its morphological and physiological properties.

Deposits on the surfaces of metal plates and ceramic tiles, which had been immersed in the seawater of a dockyard located at Ehime, Japan for approximately 8 months, were taken as microbial sources of seawater habitants. Microorganisms were also collected from the sludge accumulated on the inner surface of a drainpipe buried under the building of the authors' laboratory, and from corroded dregs of pipe 
fastenings on a wastewater tank wall at Hirano Sewage Works in Osaka, Japan. Bacterial strains of the seawater origin were grown in LBS medium $(10 \mathrm{~g}$ polypepton, $5 \mathrm{~g}$ yeast extract and $0.5 \mathrm{~g} \mathrm{~K}_{2} \mathrm{HPO}_{4}$ in $750 \mathrm{dm}^{3}$ of seawater as well as $250 \mathrm{dm}^{3}$ of distilled water, $\mathrm{pH}$ 7.6), and strains originating from the drainpipe and wastewater tank were cultured in LB broth (10 g polypepton, $5 \mathrm{~g}$ yeast extract, $10 \mathrm{~g} \mathrm{NaCl}$ per $\mathrm{dm}^{3}$ of distilled water, $\mathrm{pH}$ 7.2). The concentration of $\mathrm{NaCl}$ in LB broth was changed when necessary.

Coupons of stainless steel (SUS 304, $0.3 \mathrm{~mm}$ in thickness) and copper ( $99.96 \% \mathrm{Cu}, 0.3 \mathrm{~mm}$ in thickness) as well as wires of stainless steel (SUS 304, $0.3 \mathrm{~mm}$ in diameter) and copper (JIS C 3102, $0.3 \mathrm{~mm}$ in diameter) were purchased commercially, and then cut to desired sizes. The copper coupon surface was prepared by using 2000-grid polishing paper and liquid abrasive. All the applied metals were cleaned and sterilized in $70 \%$ ethanol prior to use.

The collected bacterial deposits were incubated individually at $25^{\circ} \mathrm{C}$ under $100 \mathrm{rpm}$ rotary shaking using glass flasks with $50 \mathrm{~cm}^{3}$ of the corresponding liquid medium in which the stainless steel coupon $(5 \times 2$ $\mathrm{cm}^{2}$ ) was placed horizontally. Each coupon was picked up weekly, and, after being washed with each medium, it was transferred to a flask with fresh medium. After one month incubation, attached cells on each coupon were recovered and spread on appropriate agar plates incubated at $25^{\circ} \mathrm{C}$. This process of culturing cells on liquid and agar plate media was repeated several times to complete the isolation of microbes.

The isolated bacterial strains were cultured with a stainless steel or copper coupon $\left(5.5 \times 6.5 \mathrm{~cm}^{2}\right)$ in a glass beaker containing $350 \mathrm{~cm}^{3}$ of LBS medium or LB broth. The applied coupons were installed vertically on a silicone rubber fixed at the bottom of the beaker. Each strain was incubated at $25^{\circ} \mathrm{C}$ with rotary shaking at $100 \mathrm{rpm}$. After a 2-week incubation, each coupon was picked up and rinsed in physiological saline with magnetic stirring. The coupon was soaked in $10 \mathrm{~cm}^{3}$ of cell lysis solution ( $1 \%$ SDS in $0.2 \mathrm{M} \mathrm{NaOH}$ ) for $2 \mathrm{~h}$, followed by the measurement of the optical absorbance at $280 \mathrm{~nm}$ for the estimation of total protein. Cell density per metal surface area was calculated from the amount of total protein through a calibration line determined separately using cell suspensions of individual isolates.

Phylogenetic analysis based on 165 rDNA sequencing for isolated cells was performed as follows. For the amplification of a partial DNA sequence encoding $16 \mathrm{~S}$ rRNA, a pair of forward (5'-TAATG GATCCTNANACATGCAAGTCGAKCG-3') and reverse (5'-CGGCA AGCTTACGGGCGGTGTGTRC-3') primers were applied (Wise et al., 1997). The DNA fragment, amplified to a predicted extent (approximately $1.4 \mathrm{kbp}$ ), was cloned into a pUC18 vector and DNA sequence was determined by a commercial service (Nisshinbo Industries Inc., Japan). Databases in DNA Data Bank in Japan (DDBJ) were searched for the similarity of $16 \mathrm{~S}$ rDNA sequences among related bacterial strains through a BLAST system (National Institute of Genetics, Japan). DNA sequences were aligned using ClustalX ver. 1.81 software (Thompson et al., 1997) and the phylogenetic tree was constructed by the N-J method (Saitou and Nei, 1987).

In the cultures with the metal wire, the bacterial cells were grown in a flask containing $100 \mathrm{~cm}^{3}$ of LB broth at $25^{\circ} \mathrm{C}$ with and without shaking. After a prescribed period of incubation, the metal wire was taken out of the flask and then rinsed in the saline for a minute. The cells attached onto the wire surface were removed by immersing the wire in the cell lysis solution. The wires were rinsed in ethanol, dried and then subjected to scanning electron microscopy (SEM) and energy-dispersive $\mathrm{X}$-ray spectroscopy (EDX). The cell density on the wire surface was determined in a similar manner as employed in the case of the metal coupons.

Using the samples obtained from the seawater environment, drainpipe and pipe fastening, microbes capable of attaching to and growing on the stainless steel surface were enriched by means of a series of liquid cultures and colony isolation. The microbes isolated on agar plates could be conveniently categorized into eight kinds according to the colony morphology (sizes, colorings, and surface and edge appearance) and microscopic observation (dimensions and shapes of cells). In order to compare the isolates' ability to attach onto a solid surface, the cell densities of selected isolates on the stainless steel surface were measured after 2 weeks of cultivation. Among the examined isolates, a bacterial strain from the wastewater source, named as WW2, showed the highest cell density of $1 \times 10^{8} \mathrm{cells} / \mathrm{cm}^{2}$, the value of which was 14 times greater than Escherichia coli (strain MM294) examined as a control. Strain WW2 also exhibited abundant ability to attach onto the copper surface $\left(1.5 \times 10^{8}\right.$ cells $/ \mathrm{cm}^{2}$ after 2 weeks of cultivation), although some bacterial cells are known to show poor ability to attach to copper surfaces owing to the antibacterial nature of copper (Brown et al., 2001; Mulligan et al., 2003; Rogers et al., 1994). Further work will be undertaken to examine the influences of material properties such as surface roughness on the ability of strain WW2 to attach onto surfaces. 
It was reported that medium osmolarity exerted an effect on the attachment of cells onto surfaces and biofilm formation in cultures of Streptococcus gordonii (Loo et al., 2000), enteroaggregative E. coli (Sheikh and Hicks, 2000) and Staphylococcus epidermidis (Rachid and Ohlsen, 2000). In the present study, the influence of medium osmolarity on WW2 cell attachment onto the stainless steel surface was investigated using LB medium supplemented with $\mathrm{NaCl}\left(0,5,10,15\right.$ and $\left.20 \mathrm{~g} / \mathrm{dm}^{3}\right)$ as an osmolyte. As shown in Fig.1, the highest cell density on the surface was observed in the medium with 15 $\mathrm{g} / \mathrm{dm}^{3} \mathrm{NaCl}$. The growth rate of strain WW2 was substantially unchanged in the range of $\mathrm{NaCl}$ concentrations examined (data not shown). It was thus suggested that an appropriate level of osmotic stress can be a stimulus to the attachment of WW2 cells onto the solid surface, as likewise found in some kinds of biofilm-forming bacteria.

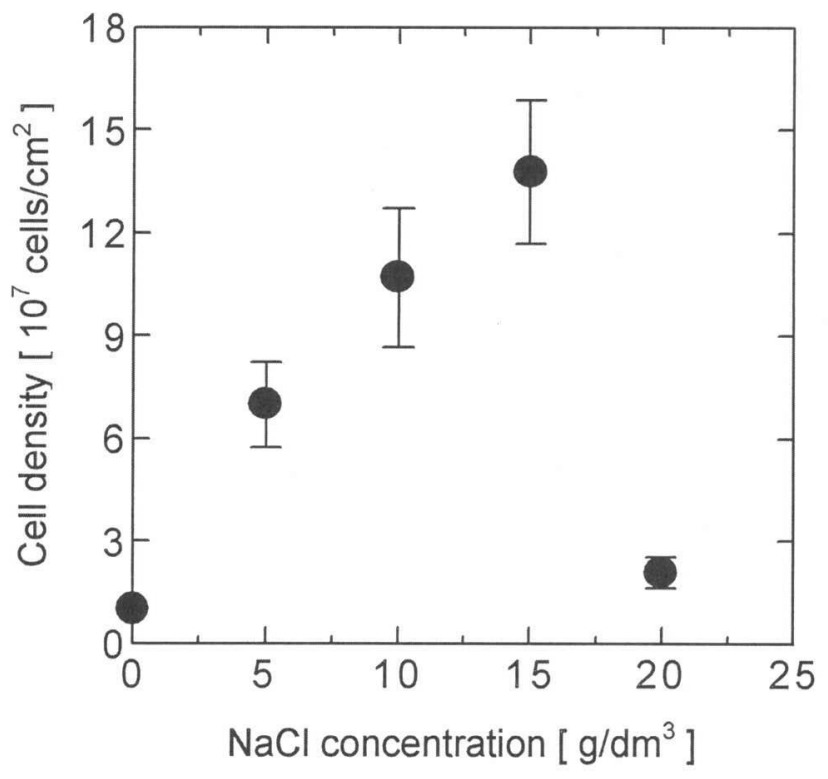

FIG. 1. Effect of $\mathrm{NaCl}$ concentration on the attachment of strain WW2 cells onto a stainless steel surface. Strain WW2 was grown for 2 weeks using LB broth with $0-20$ $\mathrm{g} / \mathrm{dm}^{3} \mathrm{NaCl}$ in which a stainless steel coupon was included.

FIG. 2. SEM images of strain WW2 adhering to stainless steel and copper surfaces. (A) and (B) Individual cells and colonial clusters on a stainless steel surface, respectively; (C) and (D) Individual cells and colonial clusters on a copper surface, respectively. Strain WW2 was grown for 2 weeks using LB broth in which the metal coupons were included. The coupons were submitted to SEM observation (S-5000L, Hitachi Co., Japan) after sputter coating with platinum according to Stewart et al. (1995).
(A)

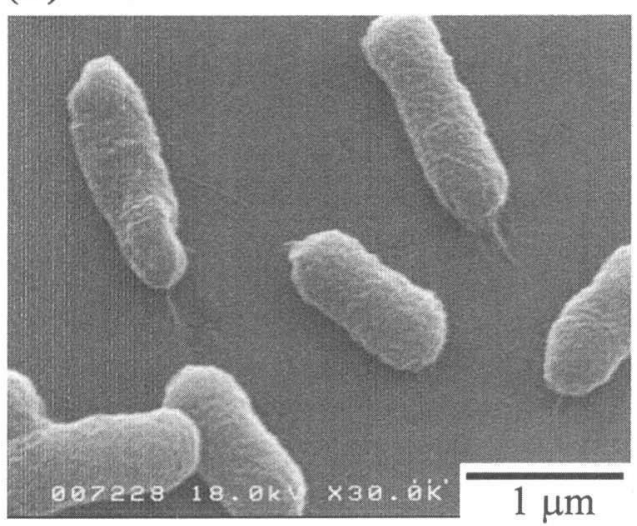

(B)

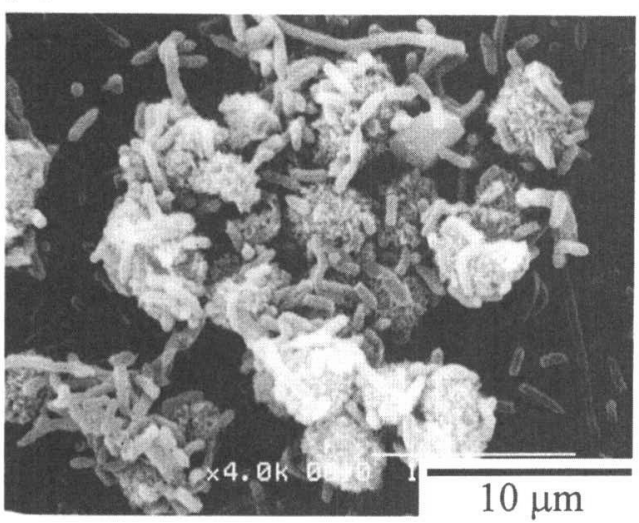

(C)

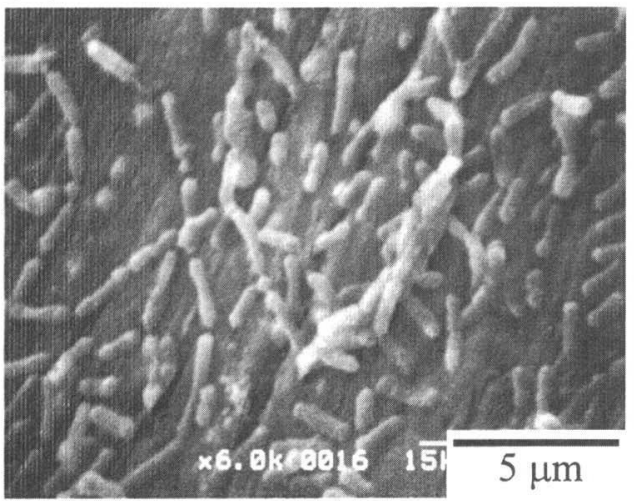

(D)

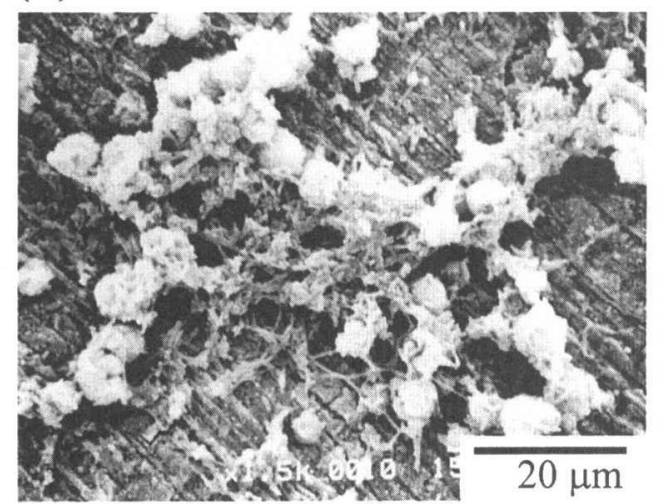


Figure 2 presents the SEM images of individual cells and colonial clusters of strain WW2 adhering to the stainless steel and copper coupons after 2 weeks of incubation, demonstrating that the cells were short bacilli sized ca. $0.75 \mu \mathrm{m}$ wide and $2 \mu \mathrm{m}$ long. A polar flagellum protruding from the cell surface was observed (Fig. 2A). As seen in Fig. 2B and D, WW2 cells were apt to form overlapping and entangled microcolonies on the surfaces of both the stainless steel and copper coupons.

Some characteristics of strain WW2 are summarized in Table 1. From physiological tests, strain WW2

TABLE 1. Some characteristics of strain WW2.

\begin{tabular}{|c|c|}
\hline Cell shape & Rods $(0.75$ by $2 \mu \mathrm{m})$ \\
\hline Response to $\mathrm{O}_{2}$ & Facultative anaerobic \\
\hline Flagellum & Observed \\
\hline Gram stain & Negative \\
\hline Catalase test & Positive \\
\hline Sulfide production & $\begin{array}{l}\text { Abundant on sulfide indole motility } \\
\text { medium under anaerobic conditions }\end{array}$ \\
\hline 16S rDNA homology & $\begin{array}{l}98 \% \text { homology to } P \text {. stuartii and } \\
P \text {. alcalifaciens }\end{array}$ \\
\hline
\end{tabular}

was a facultative anaerobic, gram-negative bacterium and classified into an Enterobacteriance family by reference to Bergey's Manual of Determinative Bacteriology (Holt 1994). In the phylogenetic analysis based on the 16S rDNA sequence, as seen in Fig.

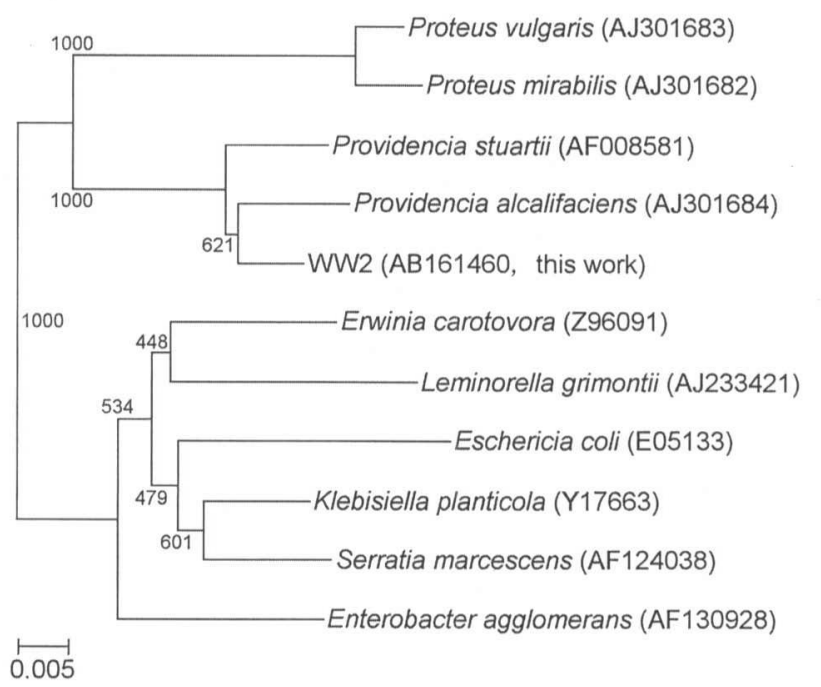

FIG. 3. Phylogenetic tree based on $16 \mathrm{~S}$ rDNA sequence analysis among Enterobacteriaceae family. The numerals noted at the branches indicate bootstrap probability and the scale bar means 0.005 substitutions per nucleotide position. The accession number is shown in the parentheses.
(A)

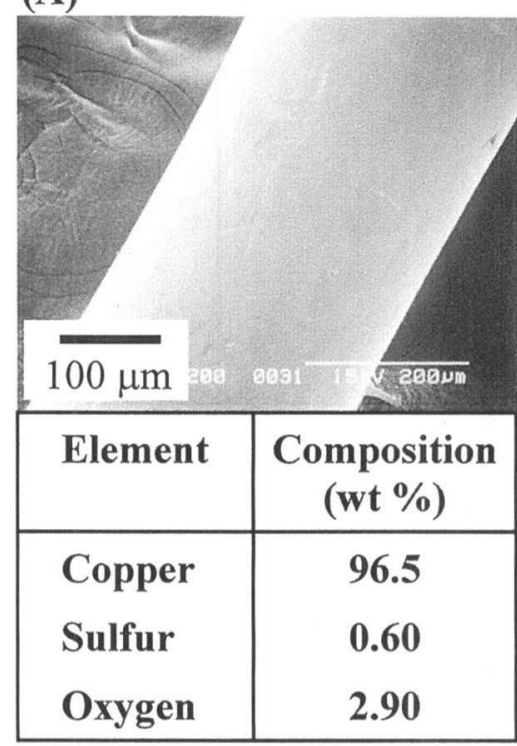

(B)

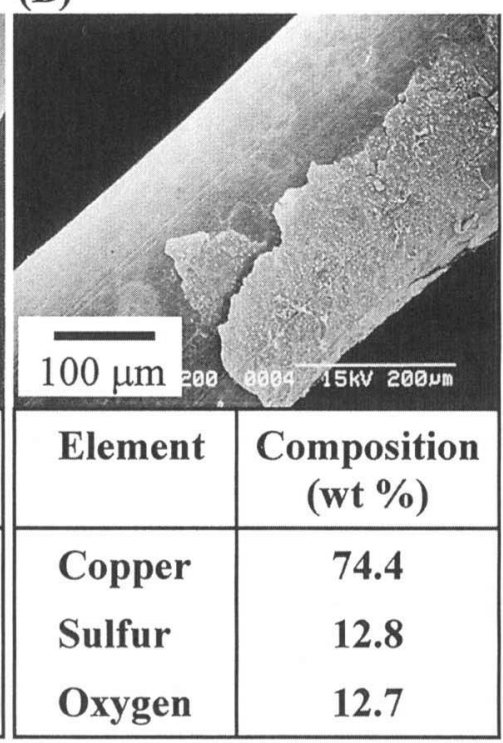

(C)

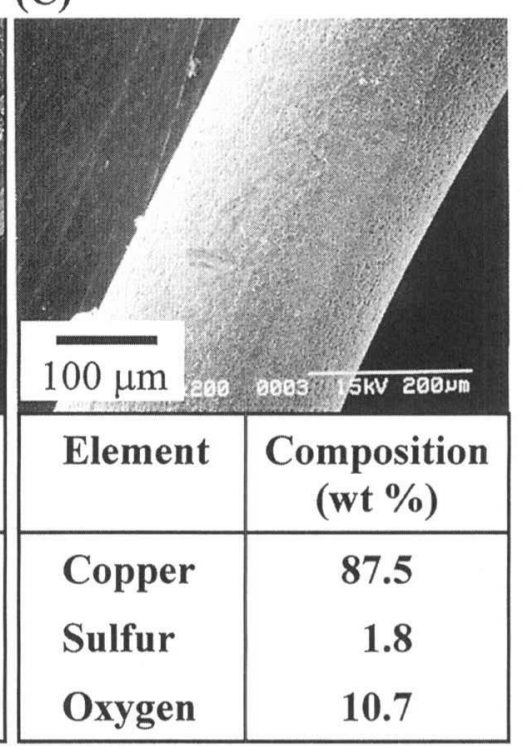

FIG. 4. SEM images of and analytical results for copper wires incubated in cultures of strain WW2. (A) Control wire as received; (B) wire incubated without shaking; (C) wire incubated with shaking. Strain WW2 was grown for 3 weeks using LB broth in which the copper wire was included. The copper wire was submitted to SEM observation (S-2250N, Hitachi Co., Japan) and EDX analysis (S-2360N, Japan Philips, Co., Japan). The elemental composition of copper wire was recorded, on a weight basis, as an average of five measurements randomly conducted on the wire surface. 
3 , the closest match was obtained with the sequences of Providencia alcalifaciens and $P$. stuartii with a homology of $98 \%$ (Table 1). Thereby strain WW2 was designated Providencia sp. WW2 in the present study.

The interaction of WW2 cells with the metal surfaces was investigated in the cultures containing wire made of stainless steel or copper. The SEM and EDX analyses indicated that no significant difference was recognized between the surfaces of stainless steel wires before and after three weeks of incubation (data not shown). On the other hand, as shown in Fig. 4B, in the case of copper wire incubated without shaking, the SEM image displayed that the wire surface possessed island-like coverings, which corresponded to black colored spots on the wire surface. The EDX analysis revealed that the black spots on the wire surface contained copper and sulfur as main elements. However, sulfur was negligibly detected on the surface of copper wire incubated with WW2 cells subjected to shaking (Fig. 4C). The amounts of attached cells were $5.3 \times 10^{8}$ and $2.7 \times 10^{8} \mathrm{cells} / \mathrm{cm}^{2}$, respectively, on the copper wires incubated for three weeks under shaking and non-shaking conditions. In the physiological examination, as shown in Table 1, it was confirmed that strain WW2 produced sulfide under anaerobic conditions, which may have resulted from the catabolic degradation of sulfur-containing amino acids, as recognized in E. coli (Sekowska et al., 2000). In the case of the copper wire incubated without shaking, therefore, it was considered that CuS precipitation occurred on the wire surface through the reaction between partially leached copper ions and bacterial sulfide ions under a locally created condition of oxygen limitation.

\section{ACKNOWLEDGMENTS}

This study was supported in part by a grant from Steel Industry Foundation for the advancement of environmental protection technology, Japan. The authors thank Dr. T. Yano, Marine Resources and Environment Research Institute, National Institute of Advanced Industrial Science and Technology, Japan, for his support in collecting microbial samples. The authors are grateful to Mr. M. Kawashima [Gas-Hydrate Analyzing System (GHAS)], Division of Chemical Engineering, Osaka University, for his technical advice.

\section{REFERENCES}

Angell, P. (1999) Understanding microbially influenced corrosion as biofilm-mediated changes in surface chemistry. Environ. Biotechnol., 10, 269-272.

Brown, C. J., Eaton, R. A., and Thorp, C. H. (2001) Effects of chromated copper arsenate (CCA) wood preservative on early fouling community formation. Mar. Pollut. Bull., 42, 1103-1113.

Dexter, S. (1993) Role of microfouling organisms in marine corrosion. Biofouling, 7, 97-127.

Ford, T. E., Searson, P. C., Harris, T., and Mitchel, R. (1990) Investigation of microbiologically produced hydrogen permeation through palladium. J. Electrochem. Soc., 137, 1175-1179.

Holt, J. G. (1994) Bergey's Manual of Determinative Bacteriology, 9th edn. Williams and Wilkins, New York.

Kjelleberg, S., and Molin, S. (2002) Is there a role for quorum sensing signals in bacterial biofilms? Curr. Opin. Microbiol., 5, 254-258.

Liu, Y., and Tay, J. H., (2001) Metabolic response of biofilm to shear stress in fixed film culture. J. Appl. Microbiol., 90, 337-342.

Loo, C. Y., Corliss, D. A., and Ganeshkumar, N. (2000) Streptococcus gordonii biofilm formation: Identification of genes that code for biofilm phenotypes. J. Biotechnol., 182, 1374-1382.

Mulligan, A. M., Wilson, M., and Knowles, J. C. (2003) The effect of increasing copper content in phosphate based glasses on biofilms of Streptococcus sanguis. Biomaterials, 24, 1797-1807.

Rachid, S., and Ohlsen, K. (2000) Effect of subinhibitory antibiotic concentrations on polysaccharide intercellular adhesin expression in biofilm-forming Staphylococcus epidermidis. Antimicrob. Agents Chemother., 44, 33573363.

Rogers, J., Dowsett A. B., Dennis P. J., Lee J. V., and Keevil, C. W. (1994) Influence of temperature and plumbing material selection on biofilm formation and growth of Legionella pneumophila in a model potable water system containing complex microbial flora. Appl. Environ. Microbiol., 60, 1585-1592.

Saitou, N., and Nei, M. (1987) The neighbor-joining method: A new method for reconstructing phylogenetic trees. Mol. Biol. Evol., 4, 406-425.

Sekowska, A., Kung, H., and Danchin, A. (2000) Sulfur methabolism in Escherichia coli and related bacteria: Facts and fiction. J. Mol. Microbiol. Biotechnol., 2, 145177.

Sheikh, J., and Hicks, S. (2000) Roles for Fis and YafK in biofilm formation by enteroaggregative Escherichia coli. Mol. Microbiol., 41, 983-997.

Stewart, P. S., Murga, R., and Srinivasan, R. (1995) Biofilm structural hetereogeneity visualized by three microscopic methods. Wat. Res., 29, 2006-2009.

Tanji, Y., Morono, Y., Soejima, A., Hori, K., and Unno, H. (1999) Structural analysis of a biofilm which enhances carbon steel corrosion in nutritionally poor aquatic environments. J. Biosci. Bioeng., 88, 551-556.

Thompson, J. D., Gibson, T. J., Plewniak, F., Jeanmougin, F., and Higgins, D. G. (1997) The ClustalX windows interface: Flexible strategies for multiple sequence alignment aided by quality analysis tools. Nucleic Acids Res., 24, 4876-4882.

Wise, M. G., Mcarthur, J. V., and Shimkets, L. J. (1997) Bacterial diversity of a Carolina bay as determined by 16S rRNA gene analysis: Confirmation of novel taxa. Appl. Environ. Microbiol., 63, 1505-1514. 